\title{
0 conhecimento para preservar a vida: um tema delicado
}

Damaris Gomes Maranhão é professora do curso de pósgraduação em Gestão e Formação em Educação Infantil do ISE Vera Cruz e do curso de Enfermagem da Universidade de Santo Amaro. É doutora em Ciências da Saúde pela Universidade Federal de São Paulo.

Contato: damaranhao@uol.com.br

\section{Resumo}

Este artigo aborda os principais riscos à saúde das crianças que frequentam creches a partir de uma análise dos dados de mortalidade noticiados na imprensa e de revisão de literatura científica sobre o tema. Descreve um programa de formação para professores de educação infantil que vem sendo desenvolvido em rede de creches como uma das medidas que podem contribuir para a segurança das crianças. 0 professor adquire competências para ponderar os riscos reais frente aos imaginários, considerando seu conhecimento e compromisso com cada uma das crianças do grupo, no sentido de apoiá-las para explorar ambientes, brincadeiras e situações de aprendizagem com prazer e segurança.

Palavras-chave: segurança; primeiros socorros; creche; educação infantil.

\section{Abstract}

This article discusses the main health risks for children attending in daycare center based on the analysis of mortality data reported both in the press and in reviews from scientific literature on the subject. It also describes a training program developed for teachers of these day care centers for early basic children education as a series of measures aiming at contributing to children's safety. The 
teachers acquires skills in order to face the real risks within the imaginaries, considering their knowledge and commitment to each group of children, in order to support them to explore different environments, play games and establishing learning situations with pleasure and safety. Keywords: safety; first-aid; daycare; kindergarten.

Algumas situações assustam por nos confrontar com a fragilidade da vida e, ao mesmo tempo, nos desafiam a buscar conhecimentos e meios para protegê-la. Os fatos a que nos referimos neste artigo dizem respeito àqueles que, ainda que pareçam imponderáveis, não o são, embora, às vezes, prefiramos negá-los, o que impede de usar o conhecimento científico acumulado pela humanidade para prevê-los e evitá-los.

Infelizmente, nos últimos anos a mídia tem noticiado mortes de crianças em contexto da Educação Infantil, fatos que assustam familiares e profissionais que compartilham os cuidados e a educação dos menores de cinco anos. A ampla divulgação dos casos, às vezes de forma sensacionalista, contribui mais para o pânico dos familiares, e professores e para reiterar o preconceito histórico relativo à creche, do que para esclarecer os interessados. 0 reconhecimento de que os cuidados com a segurança e o bem-estar das crianças devem ser integrantes da educação infantil levou o Ministério da Educação à incluir este tema entre as Orientações Curriculares Nacionais publicadas para Consulta Pública no segundo semestre de 2010.

Entre outros critérios para promover a saúde das crianças no contexto de educação infantil, o documento recomenda que o professor:

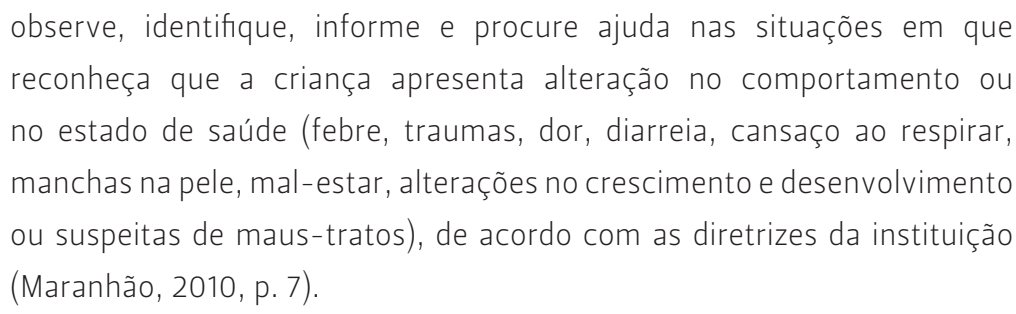

Durante a consulta pública foram recebidas críticas e sugestões dos coordenadores, gestores e professores de educação infantil das diversas regiões do país, evidenciando que alguns compreenderam que a atribuição citada não é abordada nos cursos de Pedagogia e nos programas de formação continuada em serviço, assim não poderia ser do professor, mas de outra categoria profissional 
a competência de prestar socorro médico. Argumentam que este cuidado é de responsabilidade dos profissionais de saúde, desconsiderando que os primeiros cuidados que preservam a vida e evitam as complicações devem ser prestados por quem está mais próximo da criança no momento.

As Orientações Curriculares partem do pressuposto que o professor interage e cuida da criança em parceria com a família, trocando informações diárias, o que o torna uma pessoa privilegiada para identificar as primeiras alterações de comportamento e da aparência da criança que podem ser indicativas de alteração no seu estado de saúde.

Não apenas os professores, mas todos os profissionais que trabalham em instituições de Educação Infantil, e em outros ciclos de ensino, desde que participem de programas de formação que contemplem as competências para observar, registrar e cuidar da criança em contexto educativo, são as pessoas mais próximas para reconhecer os primeiros sinais e evitar complicações.

Este artigo tem como objetivo descrever os principais riscos à criança e apresentar um projeto de formação para profissionais que trabalham em instituições de educação infantil para habilitálos para o suporte básico de vida nas situações de emergência.

\section{Morte de crianças em creches: é possível evitá-las}

A maioria das mortes de crianças divulgadas pela imprensa foi causada por asfixia por broncoaspiração - expressão técnica para a introdução nas vias aérea inferiores de alguma substância, alimento ou objeto, sólido ou líquido, que dificulta ou obstrui a passagem do ar. Esta ocorrência pode ser causada pela aspiração do próprio vômito ou regurgitação do conteúdo estomacal, que causa asfixia aguda ou complicações posteriores que pode evoluir para óbito.

Com base nos dados obtidos por meio de consulta realizada no mês de agosto de 2011, no sistema de busca Google, a partir da expressão "morte de criança em creche", apresentada no Quadro I, constata-se que ocorreram 31 mortes em instituições de educação infantil no período compreendido entre 2006 e 2011. A hipótese causal mais frequente foi a broncoaspiração ou asfixia, em alguns casos como consequência de complicações decorrentes de infecções, seguida por morte súbita ou parada cardiorrespiratória, a esclarecer: trauma, afogamento e intoxicação. As mortes 
ocorreram em instituições privadas, filantrópicas e públicas situadas em diversas regiões da cidade e do estado de São Paulo e de outras cidades e estados do país. Observa-se que parte delas funcionava de forma irregular, ou seja, sem autorização para funcionamento e com infraestrutura e recursos humanos inadequados.

Quadro I - Morte de crianças no ambiente da creche divulgadas pela imprensa, segundo idade, região, tipo de creche, data e hipótese causal

\begin{tabular}{|c|c|c|c|c|}
\hline Nome & Idade & Região & Creche & Hipótese causal \\
\hline $\begin{array}{l}\text { Agosto, } \\
2006\end{array}$ & 4 meses & $\begin{array}{l}\text { Muriaé, } \\
\text { Minas Gerais }\end{array}$ & Pública & Broncoaspiração \\
\hline $\begin{array}{l}\text { Mês não } \\
\text { identificado, } \\
2007\end{array}$ & $\begin{array}{l}1 \text { ano e } \\
4 \text { meses }\end{array}$ & $\begin{array}{l}\text { Cataguases, } \\
\text { Minas Gerais }\end{array}$ & $\begin{array}{l}\text { Não há } \\
\text { dados }\end{array}$ & $\begin{array}{l}\text { Intoxicação por organofosforado } \\
\text { empregado como inseticida } \\
\text { na creche }\end{array}$ \\
\hline $\begin{array}{l}\text { Mês não } \\
\text { identificado, } \\
2007\end{array}$ & $\begin{array}{l}1 \text { ano e } \\
5 \text { meses }\end{array}$ & $\begin{array}{l}\text { Cataguases, } \\
\text { Minas Gerais }\end{array}$ & $\begin{array}{l}\text { Não há } \\
\text { dados }\end{array}$ & Intoxicação por organofosforado \\
\hline $\begin{array}{l}\text { Setembro, } \\
2007\end{array}$ & 4 meses & $\begin{array}{l}\text { Blumenau, } \\
\text { Santa } \\
\text { Catarina }\end{array}$ & Filantrópica & Causa desconhecida \\
\hline $\begin{array}{l}\text { Julho, } \\
2008\end{array}$ & 12 meses & $\begin{array}{l}\text { Ourinhos, } \\
\text { São Paulo }\end{array}$ & Irregular & Parada cardiorrespiratória \\
\hline $\begin{array}{l}\text { Julho, } \\
2008\end{array}$ & 7 meses & $\begin{array}{l}\text { São Paulo, } \\
\text { São Paulo }\end{array}$ & Particular & $\begin{array}{l}\text { Refluxo, meningite ou parada } \\
\text { cardiorrespiratória }\end{array}$ \\
\hline $\begin{array}{l}\text { Julho, } \\
2008\end{array}$ & 3 meses & $\begin{array}{l}\text { São Paulo, } \\
\text { São Paulo }\end{array}$ & Irregular & Sufocamento ou morte súbita \\
\hline $\begin{array}{l}\text { Agosto, } \\
2008\end{array}$ & 2 anos & $\begin{array}{l}\text { Embu, } \\
\text { São Paulo }\end{array}$ & Irregular & Engasgo \\
\hline $\begin{array}{l}\text { Agosto, } \\
2008\end{array}$ & 5 meses & $\begin{array}{l}\text { Embu-Guaçu, } \\
\text { São Paulo }\end{array}$ & $\begin{array}{l}\text { Não há } \\
\text { dados }\end{array}$ & $\begin{array}{l}\text { Insuficiência respiratória } \\
\text { ou morte súbita }\end{array}$ \\
\hline $\begin{array}{l}\text { Setembro, } \\
2008\end{array}$ & 6 meses & $\begin{array}{l}\text { Ribeirão } \\
\text { Preto, } \\
\text { São Paulo }\end{array}$ & $\begin{array}{l}\text { Não há } \\
\text { dados }\end{array}$ & $\begin{array}{l}\text { Aspiração, parada } \\
\text { cardiorrespiratória }\end{array}$ \\
\hline
\end{tabular}


continua...

\begin{tabular}{|c|c|c|c|c|}
\hline Nome & Idade & Região & Creche & Hipótese causal \\
\hline $\begin{array}{l}\text { Setembro, } \\
2008\end{array}$ & 20 meses & $\begin{array}{l}\text { São Paulo, } \\
\text { São Paulo }\end{array}$ & Irregular & Varicela \\
\hline $\begin{array}{l}\text { Dezembro, } \\
2008\end{array}$ & 4 meses & $\begin{array}{l}\text { Campo } \\
\text { Grande, } \\
\text { Mato Grosso }\end{array}$ & Irregular & Aspiração de leite \\
\hline $\begin{array}{l}\text { Março, } \\
2009\end{array}$ & 5 meses & $\begin{array}{l}\text { São Paulo, } \\
\text { São Paulo }\end{array}$ & Pública & $\begin{array}{l}\text { Asfixia mecânica, } \\
\text { broncoaspiração }\end{array}$ \\
\hline $\begin{array}{l}\text { Maio, } \\
2009\end{array}$ & 5 anos & $\begin{array}{l}\text { Joinville, } \\
\text { Santa } \\
\text { Catarina }\end{array}$ & Pública & $\begin{array}{l}\text { Traumatismo por queda da } \\
\text { madeira que sustentava } \\
\text { o balanço no parque }\end{array}$ \\
\hline $\begin{array}{l}\text { Setembro, } \\
2009\end{array}$ & 5 anos & $\begin{array}{l}\text { Teresina, } \\
\text { Piauí }\end{array}$ & $\begin{array}{l}\text { Não há } \\
\text { dados }\end{array}$ & $\begin{array}{l}\text { Desmaio e parada } \\
\text { cardiorrespiratória }\end{array}$ \\
\hline $\begin{array}{l}\text { Maio, } \\
2010\end{array}$ & $\begin{array}{l}\text { Não há } \\
\text { dados }\end{array}$ & $\begin{array}{l}\text { Butantã, } \\
\text { São Paulo }\end{array}$ & Pública & Aspiração, engasgo \\
\hline $\begin{array}{l}\text { Agosto, } \\
2010\end{array}$ & 3 anos & $\begin{array}{l}\text { Belo } \\
\text { Horizonte, } \\
\text { Minas Gerais }\end{array}$ & Pública & Parada cardiorespiratória \\
\hline $\begin{array}{l}\text { Outubro, } \\
2010\end{array}$ & 4 meses & $\begin{array}{l}\text { São } \\
\text { Bernardo, } \\
\text { São Paulo }\end{array}$ & Pública & Síndrome de morte súbita \\
\hline $\begin{array}{l}\text { Setembro, } \\
2010\end{array}$ & 3 anos & $\begin{array}{l}\text { Distrito } \\
\text { Federal }\end{array}$ & Filantrópica & $\begin{array}{l}\text { Traumatismo craniano por } \\
\text { queda de TV na creche }\end{array}$ \\
\hline $\begin{array}{l}\text { Setembro, } \\
2010\end{array}$ & 5 meses & $\begin{array}{l}\text { Capão } \\
\text { Redondo, } \\
\text { São Paulo }\end{array}$ & Irregular & Aspiração \\
\hline $\begin{array}{l}\text { Novembro, } \\
2010\end{array}$ & 2 anos & $\begin{array}{l}\text { Rio das } \\
\text { Ostras, } \\
\text { Rio de Janeiro }\end{array}$ & $\begin{array}{l}\text { Não há } \\
\text { dados. }\end{array}$ & Meningite \\
\hline $\begin{array}{l}\text { Novembro, } \\
2010\end{array}$ & 7 meses & $\begin{array}{l}\text { Catanduva, } \\
\text { São Paulo }\end{array}$ & Filantrópica & $\begin{array}{l}\text { Parada cardiorrespiratória } \\
\text { após aspiração }\end{array}$ \\
\hline $\begin{array}{l}\text { Dezembro, } \\
2010\end{array}$ & 5 anos & $\begin{array}{l}\text { Cariacica, } \\
\text { Espírito } \\
\text { Santo }\end{array}$ & $\begin{array}{l}\text { Não há } \\
\text { dados }\end{array}$ & $\begin{array}{l}\text { Traumatismo por queda } \\
\text { de telhado da creche }\end{array}$ \\
\hline $\begin{array}{l}\text { Dezembro, } \\
2010\end{array}$ & 5 anos & $\begin{array}{l}\text { Cariacica, } \\
\text { Espírito } \\
\text { Santo }\end{array}$ & $\begin{array}{l}\text { Não há } \\
\text { dados }\end{array}$ & $\begin{array}{l}\text { Traumatismo por queda de } \\
\text { telhado da creche (segundo } \\
\text { caso) }\end{array}$ \\
\hline
\end{tabular}


continua...

\begin{tabular}{|c|c|c|c|c|}
\hline Nome & Idade & Região & Creche & Hipótese causal \\
\hline $\begin{array}{l}\text { Abril, } \\
2011\end{array}$ & 4 meses & $\begin{array}{l}\text { Mauá, } \\
\text { São Paulo }\end{array}$ & Irregular & $\begin{array}{l}\text { Aspiração ou dificuldade } \\
\text { respiratória }\end{array}$ \\
\hline $\begin{array}{l}\text { Fevereiro, } \\
2011\end{array}$ & 15 meses & $\begin{array}{l}\text { Porto Alegre, } \\
\text { Rio Grande } \\
\text { do Sul }\end{array}$ & $\begin{array}{l}\text { Não há } \\
\text { dados }\end{array}$ & Aspiração após mamar \\
\hline $\begin{array}{l}\text { Fevereiro, } \\
2011\end{array}$ & 2 anos & $\begin{array}{l}\text { Distrito } \\
\text { Federal }\end{array}$ & Particular & Afogamento na piscina da escola \\
\hline $\begin{array}{l}\text { Maio, } \\
2011\end{array}$ & 5 meses & $\begin{array}{l}\text { Porto Alegre, } \\
\text { Rio Grande } \\
\text { do Sul }\end{array}$ & Pública & $\begin{array}{l}\text { Aspiração de conteúdo } \\
\text { estomacal ou infecção }\end{array}$ \\
\hline $\begin{array}{l}\text { Maio, } \\
2011\end{array}$ & 11 meses & $\begin{array}{l}\text { São João, } \\
\text { Minas Gerais }\end{array}$ & $\begin{array}{l}\text { Não há } \\
\text { dados }\end{array}$ & Aspiração \\
\hline $\begin{array}{l}\text { Junho, } \\
2011\end{array}$ & 4 meses & $\begin{array}{l}\text { Guaxupé, } \\
\text { Minas Gerais }\end{array}$ & Pública & $\begin{array}{l}\text { Desidratação/ Asfixia (há duas } \\
\text { semanas na creche) }\end{array}$ \\
\hline $\begin{array}{l}\text { Julho, } \\
2011\end{array}$ & 9 meses & $\begin{array}{l}\text { Votuporanga, } \\
\text { São Paulo }\end{array}$ & Pública & $\begin{array}{l}\text { Parada cardiorrespiratória } \\
\text { ou morte Súbita }\end{array}$ \\
\hline
\end{tabular}

Fonte: Dados obtidos por meio de consulta ao sistema de busca de Google, 2011.

Embora estes dados não sejam resultados de uma pesquisa científica, o que implicaria em acessar os prontuários médicos e o registro do óbito das crianças, eles são uma primeira tentativa de aproximação com esta chocante realidade para a construção de uma hipótese: existem situações de elevado risco no processo de cuidado das crianças que frequentam creches, dependendo da qualidade das instituições, das condições de vida das crianças, do acesso das famílias aos serviços de saúde e da formação dos professores.

Nos dados coletados, observou-se que algumas crianças que faleceram estavam no período de adaptação na unidade educativa. Esta característica é compatível com os resultados de uma pesquisa que investigou todas as causas de óbitos de crianças que frequentavam a rede pública municipal de São Paulo, no período de 1995 a 1999, independentes do evento final ter ocorrido no momento em que a criança estava sob cuidados da instituição ou em outro local. Este estudo evidencia maior vulnerabilidade das crianças menores de três anos que frequentam a instituição há 
menos de seis meses. Embora os autores considerem que este fato é de difícil interpretação, recomendam que nos primeiros seis meses de frequência à creche os cuidados com as crianças sejam diferenciados, com maior vigilância do serviço de saúde e dos professores (Vico; Laurenti, 2004).

A partir desses dados é possível construir algumas hipóteses. No período de adaptação, a criança estaria exposta a uma microbiota diversa daquela do meio familiar, associado ao estresse psíquico pela mudança de ambiente e ao desmame antes do sexto mês de vida, o que a torna mais suscetível às infecções. 0 retorno à creche antes de recuperar-se de uma infecção, mesmo que benigna, poderia expô-la a novos contágios e debilitá-la. 0 choro, que pode ser mais frequente no período de adaptação, poderia desencadear vômito ou regurgitação, além de aumentar a abertura da laringe, o que favorece a aspiração dos alimentos. Os educadores ainda não conhecem as manifestações e reações da criança e nem seus hábitos de sono e alimentação, dificultando o reconhecimento de alterações no estado de saúde ou o cuidado que requerem..

\section{Vulnerabilidade a infecções: como proteger as crianças?}

A pesquisa sobre mortalidade de crianças usuárias de creches municipais no período de 1995 a 1999 descreve que do total de 223 óbitos o maior número foi de crianças menores de três anos (78, $0 \%$ ) e $38,2 \%$ em menores de um ano. As doenças respiratórias foram a principal causa $(36,8 \%)$, que em $94 \%$ dos casos também atingiu menores de três anos, com predomínio das pneumonias $(80,5 \%)$. A seguir as outras doenças infecciosas e parasitárias $(31,8 \%)$, que em $71,9 \%$ atingiram os menores de três anos. Entre as infecções, destacam-se as meningocócicas (40,8\%), as gastroenterites $(24,0 \%)$ e a varicela $(17,0 \%)$ (Vico; Laurenti, 2004).

Os acidentes e violências ocuparam o terceiro lugar com $13,5 \%$, com predominância dos atropelamentos, afogamentos e agressões, ocorridas no domicílio ou na comunidade. Os autores destacam que, embora as mortes acidentais tenham ocorrido no ambiente fora da creche, necessitam de maior investigação, pois representam apenas a parcela evidente de uma relação causal complexa (Vico; Laurenti, 2004).

A importância desse estudo é evidenciar que o evento final a morte -, embora tenha ocorrido na maioria dos casos fora da 
creche, é o resultado de um processo que poderia ser identificado e tratado antes de evoluir para complicações fatais. Comparandose os dados dessa pesquisa com aqueles apresentados no Quadro I da página 258, observa-se que as infecções respiratórias e gastrointestinais, meningites e varicela foram predominantes. Estas doenças poderiam ser evitadas pela imunização, diagnóstico precoce e cuidados adequados na fase inicial.

A escola precisa manter um sistema de controle de imunização dos seus alunos e adotar precauções padronizadas na troca de fraldas, oferta de alimentos e outros cuidados cotidianos, para diminuir o risco de propagação de doenças transmissíveis no coletivo.

A prevenção requer uma comunicação eficaz entre a família e os professores, bem como a integração da escola com o serviço público de saúde local. Por exemplo, após a pesquisa citada ser divulgada, a vacina de varicela que não é prevista no calendário nacional, está disponível na rede pública para ser aplicada nas crianças usuárias de creche após o primeiro caso diagnosticado na unidade. Esse esquema depende de um sistema ágil de informação entre serviços educacionais e de saúde, o que deve incluir a formação dos professores.

A partir dessas informações, torna-se evidente que os professores necessitam desenvolver competências para identificar sinais ou comportamentos que indiquem alteração do estado de saúde da criança para adequarem os cuidados na instituição ou para decidir quando encaminhá-las ao serviço de saúde. Esses dados também alertam professores e gestores para o planejamento de um ambiente seguro para evitar acidentes e intoxicações ou outros agravos à saúde.

\section{Como evitar engasgos e acidentes}

Contas, sementes, grãos, botões, tampinhas de garrafa, pregos, pedaços de madeira são ricos materiais desestruturados para as crianças utilizarem na construção de jogos e brinquedos mas é preciso ponderar os riscos e benefícios considerando a faixa etária, as experiências prévias com estes materiais, as possibilidades do professor acompanhar cada criança no grupo, sobretudo os menores de três anos (Granja, 2009). Balões, pipocas, amendoim, balas são associados com a infância, mas oferecem riscos à integridade dos bebês e crianças que ainda não desenvolveram 
habilidades motoras orais para evitar engasgos e aspiração.

Todo material ou brinquedo disponível para as crianças, na área interna ou externa, precisa ser avaliado em relação ao risco físico, químico e biológico, como por exemplo, evitar o reaproveitamento de embalagens com resíduos potencialmente tóxicos. Recomendase seguir normas recomendadas pela vigilância sanitária para uso de produtos de limpeza, substâncias empregadas para matar ratos ou insetos ou qualquer outro produto químico antes de usá-lo no ambiente da creche.

Os cuidados e registros rigorosos para a oferta de medicamentos, mesmo quando prescritos pelo médico, visam evitar trocas, esquecimentos, erros na dosagem ou na via de administração, descritos na literatura (Natal; Maranhão, 2010).

Ao planejar e organizar o ambiente educativo, considerar as capacidades das crianças em desenvolvimento, os objetivos de cada atividade e o papel do professor durante as brincadeiras e exploração do espaço para garantir a segurança de todos.

As necessidades e o interesse de exploração dos materiais pelas crianças estão relacionados ao desenvolvimento potencial e real. Bebês entre seis e oito meses, que estão começando a sentarse, com apoio das mãos, rolar e posteriormente levantar-se, têm um interesse e necessidade que demanda espaços seguros e com possibilidade para exercitarem suas recentes aquisições motoras. Desenvolvem as habilidades manuais e do movimento de pinça pela manipulação de objetos, levando-os à boca para reconhecimento.

Ao disponibilizar materiais e brinquedos para essas crianças, avaliar se podem ser levados à boca sem risco de engasgo ou intoxicação. Objetos e situações que demandem do professor vigilância rigorosa pelo receio de causarem acidentes talvez não sejam adequados para este período do desenvolvimento.

Os bebês após o sexto mês de vida aprendem a mastigar os alimentos semissólidos e a degluti-los, neste processo podem manifestar alguma dificuldade para lidar com as novas texturas e volumes dentro da boca simultaneamente à respiração, o que pode resultar em tosse.

A tosse é um sistema de defesa potente para evitar que os alimentos entrem nos brônquios. Manobras equivocadas dos familiares ou do professor, baseadas no senso comum, como dar tapinhas nas costas, sopros na face, oferecer água ou tentar retirar 
o alimento ou objeto com os dedos sem visualizá-lo, pode, no lugar de ajudar, agravar a situação (Abder-Rahman, 2009).

A análise dos relatórios de autópsia de todas as crianças que morreram por engasgamento por corpos estranhos, entre 1996 e 2006, realizadas no Departamento de Medicina Forense da Universidade da Jordânia, resultaram em 26 casos de crianças menores de 11 anos (Abder-Rahman, 2009). Segundo o autor,

\footnotetext{
Dezesseis (61,5\%) delas eram crianças e bebês com menos de 2 anos de idade. A maioria das vítimas de engasgamento eram meninos, e a razão entre meninos e meninas foi de 1,6:1. 0 engasgamento por comida ocorreu em $17(65,4 \%)$ casos, e nove $(34,6 \%)$ casos ocorreram devido a outros tipos de materiais. 0 período do engasgamento em todos os casos ocorreu entre 10 e 19 horas, com 69,2\% dos casos ocorrendo entre 10 e 15 horas. Em geral, as comidas que causaram obstrução tinham consistência sólida, eram redondas ou ovais, de tamanho moderado e com superfície macia, como, por exemplo, pedaços de comida sem casca e sementes de frutas ou vegetais comestíveis. Os itens não comestíveis, em sua maioria, eram feitos de borracha ou plástico e tinham superfícies macias, além de alguns poucos casos de engasgamento por bola de gude e pedaços de metais ou plástico (p. 1).
}

Os pesquisadores relataram três casos de crianças menores de três anos que foram asfixiadas ao serem socorridas pelos pais que tentaram retirar o objeto com os dedos sem visualizá-lo, manobra desaconselhada. Segundo os autores, ao tentar conter a criança para retirar o objeto ela pode reagir e chorar, aumentando o risco de engasgamento. A busca pelo objeto às cegas, com os dedos, em bebês conscientes é uma manobra perigosa e fatal. Os dedos somente podem ser usados para retirar objetos ou alimentos quando estes puderem ser visualizados e a criança estiver inconsciente e sem reação. Os autores ressaltam a importância de treinamento especialmente direcionado a pessoas que cuidam regularmente das crianças (Abder-Rahman 2009).

Outro aspecto a ser reconsiderado pelos professores é a interpretação equivocada do conceito de "autonomia". Deixar a criança sozinha em situações que requeiram supervisão é negligência, como deixar as crianças tomarem mamadeira deitadas ou andando. Embora seja uma prática comum no ambiente domiciliar, e às vezes na creche, há um risco de acidente por queda com mamadeira na boca, de aspiração pela abertura da g'lote pela posição deitada e de refluxo do leite na tuba auditiva, uma vez que a posição anatômica na criança é mais retificada que no 
adulto. Esta prática, quando seguida de adormecimento da criança com os resíduos de leite na boca, é uma das causas da "cárie de mamadeira".

Todos os cuidados com a segurança da criança também são importantes na sua educação, uma vez que as crianças, em casa ou na escola, precisam de modelos e oportunidades de alimentarse na mesa e empregando os utensílios usados no seu meio cultural como copos, xícaras, pratos e talheres. Os lactentes que ainda não sentam e nem tomam leite no copo precisam ser aleitados no colo, pela oportunidade de interação e contato corporal com o adulto que os alimenta.

\section{Os cuidados durante o sono podem evitar a Morte Súbita no Berço}

Alguns casos de morte súbita de criança em creche, conforme - Quadro da página 4, foram atribuídos à aspiração de leite ou outro alimento, mas, após investigação, esta hipótese inicial foi descartada. A morte inesperada em criança sem sintomas ou que apresentava sintomas mínimos com menos de 24 horas de duração pode ser diagnosticada como morte súbita no Berço. Este tipo de morte é investigada desde a década de 1970, o que resultou em campanhas que recomendam que os bebês durmam em decúbito dorsal, o que é apontado como um cuidado protetor (Pinho; Nunes, 2011; Bergaman, 2011).

\footnotetext{
A morte súbita pode ser classificada equivocadamente como broncoaspiração, ou morte sem assistência médica ou morte de causa desconhecida. Em estudo que investigou todos os óbitos infantis pósperinatais ( 7 a 364 dias de idade) ocorridos durante um ano em 10 cidades do estado do Rio Grande do Sul, foram identificadas 72 mortes súbitas. Destes, 38 (53\%) eram crianças que não apresentaram qualquer sintoma nos últimos 7 dias de vida. Quinze crianças (21\%), até então assintomáticas, apresentaram sintomas imediatamente antes da morte: 9 com gemência ou choro, 4 com vômitos e 2 com "convulsões", segundo informações colhidas. Oito crianças $(11 \%)$ apresentaram quadro gripal leve no dia do óbito e outras $3(4 \%)$ estiveram gripadas na semana do óbito mas já estavam assintomáticas. Quatro crianças (6\%) apresentaram "ronqueira no peito" desde o nascimento mas haviam sido examinadas por médicos que não encontraram alterações pulmonares. Por fim, 4 crianças (6\%) apresentaram outros sintomas leves no dia do óbito: $1 \mathrm{com}$ diarreia, $1 \mathrm{com}$ constipação, 1 com eczema e 1 com monilíase oral (Pinho; Nunes, 2011, p. 2).
} 
0 perfil epidemiológico é semelhante ao descrito em outros países, assim como os fatores de risco. Reduzir a exposição das crianças aos vapores do tabaco e evitar a postura ventral para dormir são as medidas possíveis de intervenção, uma vez que são considerados fatores de risco: a etnia (autorreferida como negra), baixa renda familiar, gravidez na adolescência, baixo peso ao nascer; estes são determinantes complexos que implicam em investimentos sociais a longo prazo (Pinho; Nunes, 2011).

A revisão de literatura sobre a Síndrome de Morte Súbita no berço evidencia que crianças menores de seis meses que dormem de barriga para baixo têm de 3 a 9 vezes mais risco de ser acometido por esta síndrome do que aqueles que dormem de barriga para cima. Programas educativos implementados em países Europeus, Asiáticos, da Oceania e da América do Norte com o objetivo de orientar as mães para que colocassem seus lactentes para dormir na posição supina reduziram a mortalidade por esta síndrome, de 1,4 a 2,6/1000 nascidos vivos para 0,5 a 0,8/1000 nascidos vivos (Oliveira; Maranhão, 2010).

Na América Latina as mães utilizam a posição lateral para colocar os seus filhos para dormir, a qual, até então, era considerada uma posição segura, mas que vem sendo questionada devido a estudos mais recentes. Pinho e Nunes (2011) afirmam, por exemplo, que:

Em um recente estudo europeu, os fatores de risco mais significativos para a síndrome foram dormir em decúbito ventral e virar da posição de decúbito lateral para ventral. Um estudo prévio realizado por nosso grupo descobriu que $71 \%$ dos casos de SMSL dormiam geralmente na posição lateral; desses pacientes, $52 \%$ foram encontrados mortos nessa posição e $19 \%$ foram encontrados em decúbito ventral. No presente estudo, poucos lactentes costumavam dormir em decúbito ventral, provavelmente porque no Brasil aconselha-se que os lactentes durmam em decúbito lateral. De fato, a predominância da posição lateral durante o sono foi semelhante nos três grupos estudados, e, portanto, não teve aparentemente nenhum impacto no resultado. 0 fato de ter sido registrada a posição "habitual" em vez da posição na qual o lactente estava dormindo na noite do óbito ou a posição na qual foi encontrado morto foi com certeza uma limitação do presente estudo. No entanto, nossos achados corroboram estudos prévios, no sentido de afirmar que reconhecer os hábitos de sono potencialmente protetores para a SMSL e evitar práticas de sono associadas a um risco aumentado para SMSL podem ter impacto positivo na redução da incidência de SMSL em populações de regiões onde essas informações não são atualmente fornecidas ao país (p. 2). 
Esta recomendação nem sempre é conhecida pelos professores que ao serem informados da mesma argumentam que se posicionadas de barriga para cima as crianças podem vir a regurgitar ou vomitar o que, teoricamente, favoreceria a aspiração do conteúdo eliminado. Entretanto, conforme citado, as pesquisas concluem, até o momento, que a posição dorsal é a mais segura no primeiro ano de vida.

As crianças com episódios frequentes de regurgitação ou hipótese de refluxo precisam ser avaliadas pelo médico da família, que poderá orientar outros cuidados, como elevar a cabeceira do berço ou do colchonete, prescrever medicamentos e acompanhamento regular do estado geral de saúde.

\section{Conhecimento dos professores para identificação de situações de risco e para realizar manobras de suporte básico de vida}

Um estudo que investigou o conhecimento dos educadores de creches públicas do sul do país para lidar com as situações de emergência clínica, ou causadas por acidentes que acometem as crianças, evidencia a necessidade de se introduzir programas de formação para instruí-los (Silvanil et al., 2008). Os educadores pesquisados sentiam-se despreparados para socorrer as crianças que se acidentavam ou apresentavam alguma intercorrência. Lidavam com a situação com base no senso comum, nas experiências pessoais e na cultura institucional, às vezes insuficiente para a segurança da criança e do professor. A pesquisa confirma a necessidade de se oferecer cursos específicos que preparem os educadores para reconhecer os sinais de risco e agir em cada circunstância.

A formação dos professores e de todos os profissionais da escola precisa estar fundamentada em protocolos previstos para cada situação. Estes protocolos incluem os critérios que orientam o professor como agir de acordo com suas observações e avaliação do estado de saúde da criança, quando chamar a família ou acionar o serviço de resgate, como fazê-lo e como registrar a ocorrência (Catunda, 2005).

A seguir é apresentado um programa de formação desenvolvido há seis anos em rede de creches localizadas em empresas e que têm resultado em maior segurança para as crianças, familiares e para os profissionais. 


\section{Formação de competências para proteger a vida}

O Centro de Desenvolvimento Educacional (CEDUC) é um serviço especializado em gerenciamento administrativo e pedagógico de creches localizadas em empresas para atender os filhos dos trabalhadores, pais ou mães. Atualmente é responsável pela operacionalização de cinco creches que atendem 143 crianças de 4 meses a 4 anos na unidade de Cajamar; 60 crianças de 4 meses a 2 anos na unidade do bairro do Itaim; em São Paulo; 45 crianças de 4 meses a 2 anos na unidade de Interlagos, em São Paulo; 30 crianças na mesma faixa etária na unidade de Osasco; e 25 crianças na faixa etária de 4 a 36 meses na unidade de Itapecerica da Serra.

A formação continuada da equipe visa o cuidado e educação integral da criança, o que inclui a promoção da segurança. A equipe é instruída e participa regularmente de cursos que abordam a prevenção de acidentes, a habilidade para identificar os primeiros sinais ou comportamentos que indiquem alteração do estado de saúde da criança, bem como para prestar os primeiros socorros no ambiente da creche. 0 módulo formativo para o desenvolvimento de competências para o suporte básico de vida está fundamentado em bases teóricas e científicas de acordo com os protocolos atualizados da American Heart Association e European Resuscitation Council Guidelines for Resuscitation e American Hearth Association (Biarenta et al., 2010).

A abordagem do curso privilegia o desenvolvimento de competências para observação e avaliação dos sinais, sintomas e comportamentos indicativos de risco à saúde da criança associados aos procedimentos para socorrê-la no contexto da creche.

A reflexão sobre situações vivenciadas pelos professores, dentro ou fora das unidades, possibilita rever práticas com base no senso comum e ressignificá-las. A partir do relato dos participantes que já observaram ou socorreram uma criança com dificuldade respiratória, engasgada, em convulsão ou que "perdeu o fôlego", o grupo é convidado a refletir sobre quais foram os primeiros sinais observados e quais as diferenças e semelhanças no comportamento e na aparência da criança em cada uma destas situações.

Essa abordagem possibilita que os professores e a equipe da escola identifiquem precocemente os sinais mais sutis que evoluem rapidamente na criança e que podem ser revertidos antes 
que comprometa o seu estado geral. Assim, embora aprendam técnicas para desobstrução das vias aéreas e para reanimação, que podem ser empregadas por leigos em ambiente extra-hospitalar, o objetivo é que percebam e ajam antes que a criança agrave seu estado de saúde e requeira manobras mais radicais.

O programa é contínuo, com formação inicial de toda a equipe de cada unidade e revisão do conteúdo teórico e prático a cada seis meses. Esta frequência visa que todos estejam preparados para uma situação de emergência embora as ações preventivas tenham como principal objetivo evitar que ocorram.

0 curso inclui uma base teórica sobre os principais acidentes e situações clínicas que podem ocorrer em creches e noções básicas sobre o funcionamento do sistema respiratório e cardiovascular. Destaca os problemas de saúde mais prevalentes entre as crianças, que podem evoluir para insuficiência respiratória, choque e parada cardiorrespiratória. Alerta para os "sinais de perigo", ou seja, primeiros sinais e comportamentos que indicam que a criança necessita de cuidado especializado antes que o quadro evolua, com complicações.

Os conteúdos teóricos são alternados com oficinas que simulam com manequins as manobras de avaliação e de suporte básico de vida. Os participantes reunidos em pequenos grupos e orientados pelo monitor realizam as manobras para identificar e avaliar o risco de vida da "vítima", decidem o procedimento para cada situação e aprendem como comunicar o fato para obter ajuda especializada e para dar prosseguimento ao atendimento básico inicial.

À medida que participam do programa, os professores e a equipe de apoio tornam-se "veteranos" e são promovidos monitores nos próximos cursos para iniciantes. Esta "promoção" da situação de aluno para monitor implica que os participantes dominem as competências para socorrer uma criança doente ou acidentada em situação real a qualquer momento. Em cada unidade, os "veteranos" têm a função de assumir o primeiro socorro caso uma pessoa da equipe sinta-se insegura para ter a iniciativa necessária na situação real de emergência (Prefeitura do Município de Cajamar, 2010).

Durante as oficinas de simulação, o coordenador do curso, os instrutores e os monitores acompanham passo a passo o desempenho dos participantes. Esta avaliação processual possibilita abordagens individuais para esclarecer dúvidas, acolher dificuldades pessoais e aprimorar atitudes e procedimentos. 


\section{Considerações finais}

0 programa de formação de professores e profissionais de creche que inclui a prevenção de acidentes e de complicações potenciais do estado de saúde da criança tem contribuído para o aprimoramento dos cuidados infantis cotidianos. A formação torna observável para os professores as situações potenciais de risco ambiental, relativos ao estado da criança ou durante o processo de cuidar e educar.

0 professor adquire competências para ponderar os riscos reais frente aos imaginários, considerando seu conhecimento e compromisso com cada uma das crianças do grupo, no sentido de apoiá-las para explorar ambientes, brincadeiras e situações de aprendizagem com prazer e segurança.

Quando os professores aprendem a identificar os sinais de gravidade eles conseguem tomar decisões mais adequadas e prestar cuidados que evitem complicações. Esta competência é uma importante ferramenta para o professor decidir quando e como convocar os pais para comparecer à creche ou à préescola, se convém esperá-los ou se devem acionar o serviço de emergência.

Após a implantação desse programa, a maioria dos professores tem identificado situações de risco e agido em tempo de evitar complicações, conforme dados parciais de pesquisa em andamento. 0 sucesso do programa suscitou o interesse dos pais em participar de curso de prevenção de acidentes e primeiros socorros adaptado para a situação doméstica, bem como de outras instituições educativas.

\section{REFERÊNCIAS}

ABDER-RAHMAN, H. A. Engasgamento em bebês após busca às cegas com os dedos. Jornal de Pediatria. (Rio Janeiro), v.85, n.3, maio/junho 2009. Disponível em: <http://www.scielo.br/scielo.php?script=sci_arttext\&pid =S0021-75572009000300015.> Acesso em: 28 out. 2011.

BERGAMAN, A. B. Próximos passos no estudo da morte súbita do lactente. Jornal de Pediatria, Rio de Janeiro, v. 87, n. 2, mar./abr. 2011, p. 87-88. 
BIARENTA, D. et al. European Resuscitation Council Guidelines for Resuscitation 2010 Section 6. Pediatric life support. Journal Resuscitation, n. 81, 2010, p. 1364-1388. Disponível em: <www.elsevier.com/locate/resuscitation>. Acesso em: 28 out. 2011.

CATUNDA, J. K. C. Protocolo de primeiros socorros. São Paulo: CEDUC, 2005.

GRANJA, M. E a mãe a insistir ao amendoim. Rev Port Clin Geral, n. 25, 2009, p. 184-186.

MARANHÃO, D. G. Saúde e bem estar das crianças: uma meta para educadores, familiares e profissionais de saúde. In: BRASIL. Ministério da Educação. Orientações Curriculares Nacionais para a Educação Infantil. Brasília: MEC, 2011.

NATAL, T. B.; MARANHÃo, D. G. Padrão de consumo de medicamentos por crianças usuárias de creche. Trabalho de Conclusão de Curso de Graduação em Enfermagem. Universidade de Santo Amaro, São Paulo, 2011.

NUNES, M. L.; PINHO A. P. S.; AERTS, D.; ANNA, A. S.;MARTINS, M. P.; COSTA, J. C. Síndrome da morte súbita do lactente: aspectos clínicos de uma doença subdiagnosticada. Jornal de Pediatria. Rio de Janeiro, 2001 v. 77, n.1, p. 20-34. Disponível em: <www.scielo.br/pdf/jped/v77n1/v77n1a09.pdf>. Acesso em 28 out. 2011.

PINHO, A. P. S.; NUNES, M. L. Perfil epidemiológico e estratégias para o diagnóstico de SMSL em um país em desenvolvimento. Jornal de Pediatria. Rio de Janeiro, v. $87 \mathrm{n}$. 2, mar./abr. 2011. Disponível em: <http://dx.doi.org/10.1590/ S0021-75572011000200006>. Acesso em: 28 out. 2011.

PREFEITURA DO MUNICIPIO DE CAJAMAR. Diretoria de Educação. Segurança na creche, Cajamar, ano 3, n. 33, jun. de 2010.

SILVANII, C. B.; GOMESIL, G. C.; SOUSA, L. D.; SOUZA, J. L. Prevenção de acidentes em uma instituição de educação infantil: o conhecimento das cuidadoras. Rev. enferm. UERJ. Rio de Janeiro, v. 16, n. 2, 2008, p. 200-205.

VICO, E. S. R.; LAURENTI, R. Mortalidade de crianças usuárias de creches. Rev. Saúde Pública. São Paulo, v. 38, n. 1, fev. de 2004, p. 38-44.

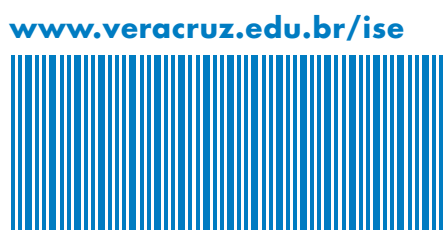

